\title{
EDUCAÇÃO AMBIENTAL E CULTURA: ARTICULANDO MÍDIA E CONHECIMENTO POPULAR SOBRE PLANTAS
}

\author{
ENVIRONMENTAL EDUCATION AND CULTURE: CONNECTING MEDIA AND POPULAR KNOWLEDGE \\ ABOUT PLANTS
}

\author{
Lucia de Fátima Estevinho Guido ${ }^{1}$ \\ Inez Reptton Dias ${ }^{2}$ \\ Gustavo Lopes Ferreira $^{3}$ \\ Aline Bertoldo Miranda ${ }^{4}$
}

Resumo $\mathrm{O}$ artigo fundamenta-se em reflexões advindas de uma pesquisa sobre as múltiplas possibilidades 'do fazer' educação ambiental, tendo como ponto de partida um estudo em etnobotânica que buscou conhecer e valorizar o conhecimento sobre plantas em distritos rurais da cidade de Uberlândia, em Minas Gerais, Brasil. A pesquisa foi realizada com crianças, jovens e pessoas da comunidade dos distritos de Tapuirama e Cruzeiro dos Peixotos mediante a utilização de diversas linguagens das mídias. As abordagens metodológicas se diferenciaram no percurso investigativo procurando adequar-se à realidade de cada distrito. A coleta de dados foi realizada por meio de diversas mídias visuais, como fotografia e vídeo. Estes instrumentos estavam presentes nas diferentes oficinas realizadas ao longo da pesquisa; na última, houve a produção coletiva do documentário Causos do Cerrado. O estudo fez interagir o local (tradição do conhecimento popular sobre as plantas) e o global (recursos tecnológicos empregados na produção midiática).

Palavras-chave educação ambiental; mídia e educação; conhecimento popular sobre plantas.
Abstract The article is based on reflections coming from research done on the multiple possibilities of 'practical' environmental education, taking, as starting point, a study on ethnobotany that sought to get to know and value popular knowledge about plants in rural districts of the city of Uberlândia, state of Minas Gerais, Brazil. The survey was conducted among children, youth, and people from the community of the districts of Tapuirama and Cruzeiro of Peixotos and used various media languages. Different methodological approaches were used in the course of the investigation in an attempt to adjust to the reality of each district. The data were collected using various visual media, such as photography and video. These tools were present in the different workshops held over the course of the research project; during the last one, there was the collective production of the documentary titled Causos do Cerrado (Stories of Savannah). The study brought interaction between local (the tradition of the folk knowledge on plants) and global (technological resources employed in media production).

Keywords environmental education; media and education; folk knowledge about plants. 


\section{Introdução}

A pesquisa apresentada neste artigo considera a riqueza do aprendizado prático sobre plantas e sua vinculação ao conhecimento popular. Trata especificamente do conhecimento popular sobre plantas do Cerrado e o modo como esse conhecimento pode ser trabalhado em atividades de educação ambiental, que interferem dinamicamente no mundo da práxis, incorporando novas vivências e transformando-as constantemente.

A educação ambiental foi discutida e trabalhada com base no desenvolvimento de pesquisas que buscaram conhecer e valorizar o conhecimento popular sobre plantas em distritos rurais do município de Uberlândia, localizado no estado de Minas Gerais. Suscitar discussões relativas a essa temática com a comunidade a partir de suas culturas permitiu verificar a possibilidade do intercâmbio entre o conhecimento construído pela educação ambiental na escola e fora dela, especialmente na comunidade onde circula o conhecimento popular sobre as plantas.

O levantamento etnobotânico foi feito em fazendas (zona rural) e em quintais das residências (zona urbana) dos distritos. Nas fazendas foram inventariadas 128 espécies de plantas, a maioria delas utilizada pelos entrevistados, e 111 são nativas do bioma Cerrado (Oliveira, 2008). Já o levantamento realizado nos quintais mostrou que há uma predominância de plantas exóticas, em que as categorias de uso mais encontradas foram a medicinal e a alimentar (Milani, Guido e Barbosa, 2011). Estes resultados indicaram que a comunidade detém o conhecimento popular sobre plantas do Cerrado, acrescidos de um conhecimento sobre o uso medicinal das espécies nativas e exóticas.

Os distritos onde foi realizado o levantamento etnobotânico ainda mantêm uma estrutura social baseada no trabalho rural, nas atividades domésticas de cuidados com a casa e seus quintais, embora muitos moradores trabalhem na sede do município. Não é possível entender essas localidades de forma isolada, uma vez que, mesmo possuindo serviços sociais essenciais, seus habitantes recebem influências principalmente da sede do município, onde muitos moradores estudam, fazem compras e frequentam atividades de lazer. Essa aproximação estabelece laços de dependência no plano social, econômico e político, trazendo outras culturas, dentre elas a capitalista-consumista, que, além de enfraquecer a cultura típica própria de pequenos povoados - 'menos consumistas' -, impulsiona a degradação dos recursos naturais.

No entanto, ao se pensar nas políticas de conservação da natureza para as comunidades estudadas, estas não podem estar fadadas a um isolamento do mundo contemporâneo, pois não seria justo que ficassem 'presas' a uma tradição, já que a sociedade lhes imputa novos desafios, novas maneiras de 
viver. Durante o levantamento do conhecimento popular sobre plantas, o grupo de pesquisa foi questionado pelos moradores sobre o retorno dos resultados obtidos pela universidade junto aos distritos. Foi acordado que o grupo de pesquisa faria atividades de educação ambiental envolvendo o conhecimento popular sobre plantas. A princípio, pensou-se em trabalhar uma educação ambiental que valorizasse a vida simples, junto a uma natureza intocada, como se ela ainda existisse. Um tipo de educação ambiental caracterizada por Guimarães (2007, p. 182) como uma tentativa de "cristalizar, fixar um 'outro' em um território e em uma tradição".

O andamento do trabalho de campo permitiu lançar um outro olhar para a educação ambiental, fruto de discussões, leituras e reflexões que o grupo foi tecendo ao longo do tempo. Assim, cogitou-se de outra perspectiva, que valoriza o conhecimento popular sobre as plantas do Cerrado, que escuta $^{5}$ e registra as falas das pessoas, especialmente as mais velhas. Para isso, empregou-se uma metodologia que se apropriou de procedimentos da etnobotânica, mas que também não deixou de incorporar as diretrizes teóricas da antropologia, acolhendo teses da hibridação cultural (Canclini, 2008; Burke, 2010). Deste modo, o trabalho respeitou o tempo das pessoas e o tempo atual que introduz outras determinações, outras maneiras de viver e de estar no mundo.

Nos distritos, loci da pesquisa, encontraram-se diferentes pessoas conhecedores de plantas, curandeiros, benzedeiras, professores, estudantes, moradores nascidos no local e os que vieram de outros lugares -, sujeitos com histórias que foram registradas e revelaram diferentes concepções de educação ambiental. Tais registros trouxeram novas significações para o grupo, que durante a pesquisa buscou confrontar as diferentes visões dos sujeitos, de modo a perceber e valorizar os traços de hibridação em sua cultura, apresentada por suas opiniões, posições e diálogos. Nesses diálogos, novas ideias foram criadas e colocadas novamente em discussão: a diferença foi percebida, valorizada e trabalhada.

\section{Pensando a educação ambiental a partir da diferença}

No questionário aplicado nas comunidades estudadas, buscou-se saber quem são os conhecedores de plantas. Os respondentes foram unânimes em apontar os mais velhos, aqueles que mantêm a tradição da cura baseada nas plantas. Aprender a cultura de sua gente, das plantas de uma determinada região e seus usos está relacionado ao mundo da práxis, de certa forma faz parte da memória coletiva, pois os entrevistados não sabem dizer como ocorreu o aprendizado, apenas fazem referências aos familiares: a aprendizagem é transmitida de geração a geração. 
Renato Ortiz (2003), na abordagem dos cultos afro-brasileiros, desenvolve argumentos baseados nos trabalhos de Goffman e Halbwachs, que tratam da memória coletiva, da sua importância para preservar a cultura, da manutenção da tradição nestes cultos. Para esse autor, “a memória coletiva só pode existir enquanto vivência, isto é, enquanto prática que se manifesta no cotidiano das pessoas" (Ortiz, 2003, p. 133).

Autores como Bosi (2003, p. 61) afirmam que "a memória devolve o que o passado vislumbrou e o presente esqueceu". Quando se 'contam ou resgatam' as lembranças de um povo, essas lembranças se tornam memórias. A autora complementa que o estudioso da memória geralmente entrevista idosos dos quais se espera o rico testemunho de outras épocas. Dessa forma, à medida que o pesquisador percebe-se envolto pelo contexto histórico preciso onde viveram seus depoentes, configura-se o campo de significações dessas lembranças e memórias.

Neste contexto, para suscitar as memórias, foi proposto para a comunidade estudada a construção coletiva de um documentário com o intuito de registrar o conhecimento popular sobre plantas medicinais e a utilização dos recursos naturais, como será explicitado no próximo tópico. O documentário é um instrumento ou, nas palavras de Peter Burke (2010), um artefato importante para o registro das lembranças e divulgação das memórias.

Em um tempo em que a mídia está muito presente no cotidiano das pessoas, a produção do documentário que registrou as narrativas de uma comunidade rural ao relembrar suas tradições e cultura foi necessária para verificar como as comunidades estudadas podem se apropriar dos meios de comunicação para registrar e divulgar o conhecimento popular, especialmente aos indivíduos mais jovens. Fischer (2008) afirma que, na investigação sobre o diálogo entre a análise de produtos midiáticos e o depoimento de jovens estudantes sobre sua relação com os meios de comunicação, pode-se compreender melhor a noção do outro, para assim construir sua própria identidade.

Portanto, o grupo de pesquisa assumiu o desafio de tratar a preservação do conhecimento popular sobre as plantas buscando o resgate da memória coletiva em torno do conhecimento sobre elas, com base em produções midiáticas. Pela atenta observação dos distritos rurais, nos últimos anos, percebe-se a necessidade de se considerar as diferentes culturas e compreender o processo de hibridação cultural nesses locais. Para Canclini (2008, p. 8), o termo hibridação se refere "aos processos socioculturais em que as estruturas ou práticas discretas, que existiam em forma separadas, se combinam para gerar novas estruturas, objetos e práticas".

Assim, essas novas bases teóricas passaram a sustentar as reflexões do grupo, que, ao se alinhar às ideias de Canclini, compreende não ser possível 
estudar as culturas populares como se fossem 'autogeradas', autênticas ou tradicionais. Deve-se considerar seu caráter híbrido, em que as mesclas culturais podem ser produzidas por justaposições, negociações e, por vezes, sujeição entre diferentes culturas.

Canclini propõe ainda a superação dos enquadramentos entre o que é culto e popular, partindo da ideia de cultura urbana. Deste modo, a expansão das cidades intensificou os processos de hibridação cultural:

Passamos de sociedades dispersas em milhares de comunidades rurais com culturas tradicionais, locais e homogêneas, em algumas regiões com fortes raízes indígenas, com pouca comunicação com o resto de cada nação, a uma trama majoritariamente urbana, em que se dispõe de uma oferta simbólica heterogênea, renovada por uma constante interação do local com redes nacionais e transnacionais de comunicação (Canclini, 2008, p. 285).

Deste modo, buscou-se compreender como as comunidades percebem e se afetam por outras culturas, sobretudo pela cultura urbana, centrada nas tecnologias eletrônicas e nos processos audiovisuais como forma de produção do real. Buscou-se também verificar as possibilidades de identificação ou estranhamento com essas práticas culturais. A adaptação dessas comunidades à vida moderna consiste de processos de hibridação vivenciados por elas, por isso: “Estudar processos culturais (...) mais que levar-nos a afirmar identidades autossuficientes, serve para conhecer formas de situar-se no meio da heterogeneidade e entender como se produzem as hibridações" (Canclini, 2008, p. 11).

$\mathrm{O}$ autor citado insiste na importância de verificar como funcionam as hibridações, como se produzem novas práticas e como podem ocorrer: de maneira espontânea ou pela iniciativa individual e coletiva, como uma capacitação profissional, um conjunto de saberes e técnicas que são empregados para se obter novas condições de produção dos modos de vida.

Na pesquisa apresentada neste artigo buscaram-se formas de trabalhar com a educação ambiental a partir do conhecimento local sobre plantas, um conhecimento vindo das pessoas da comunidade, que tentam reafirmar a cultura local em resposta ao processo de globalização, mas que também se ajustam e se empenham pelos benefícios da vida moderna.

O trabalho de educação ambiental desenvolvido com as comunidades dos distritos de Uberlândia não se limitou a valorizar apenas a cultura local, mas em auxiliar essas comunidades a se integrarem em um mundo não de identidades fixas e sim múltiplas, com movimentos de idas e vindas a lugares distantes, admitindo ainda a virtualidade do processo, pois mesmo as pessoas que nunca saíram do local podem, graças aos meios de comunicação, conhecer 'o mundo' e suas culturas. 
A motivação inicial da pesquisa foi investigar o saber popular sobre o cultivo de plantas medicinais em espaços híbridos, nos quais há uma interação de características dos meios urbanos e rurais. Para tanto, considerou-se uma educação ambiental baseada nos contrastes entre o comportamento tradicional e as inovações advindas da urbanização, colocando os recursos midiáticos a serviço da valorização do conhecimento popular. Neste momento, procurou-se apoio nos trabalhos de Martín-Barbero (2007), por se acreditar que os jovens estão imersos em uma experiência cultural completamente nova que intervém na maneira de ver e interpretar o mundo.

\section{Percurso metodológico}

Este artigo apresenta parte dos resultados de um projeto de pesquisa, intitulado “O potencial de uma proposta de educação ambiental articulando a cultura popular sobre plantas e a cultura midiática", 6 e teve por objetivo investigar se a construção coletiva de um documentário conecta conhecedores de plantas, jovens escolares, professores e lideranças comunitárias na valorização da cultura local, uma cultura que, produzida pela mídia, seja ressignificada em culturas que incluam os diferentes modos de viver e estar no mundo.

A pesquisa foi pautada nos domínios da abordagem qualitativa. Ludke e André (1986) afirmam que este tipo de pesquisa em educação deve ser capaz de envolver uma preocupação em pensar o contexto investigado de maneira mais ampla. Teve como sujeitos de estudo moradores de dois dos quatro distritos de Uberlândia, como já mencionado anteriormente. A inserção do grupo de pesquisa nas comunidades foi estabelecida a partir das pesquisas relacionadas ao levantamento etnobotânico, o que facilitou o envolvimento tanto das escolas quanto das comunidades na construção do documentário discutido neste artigo. Participou nesse momento da pesquisa um grupo de 20 alunos, na faixa etária entre 12 e 14 anos de idade, das escolas das duas comunidades estudadas; uma professora e a diretora de uma das escolas, bem como sete membros da comunidade identificados como conhecedores de plantas, dois deles também considerados lideranças comunitárias.

A coleta dos dados foi realizada mediante entrevistas com os conhecedores de plantas, anotações de campo e registros fotográficos e videográficos de todos os momentos da pesquisa. Estes registros foram transcritos e analisados.

Os dados apresentados neste artigo foram compilados na oficina "Produção audiovisual como resgate do conhecimento popular sobre plantas", ministrada por um profissional da área de cinema. A produção do documentário foi coletiva, uma vez que a decisão que envolveu a elaboração do 
roteiro, a escolha do local das filmagens e dos depoentes ocorreu durante esta oficina. Para a discussão do documentário, consideraram-se os depoimentos registrados no filme, bem como as entrevistas com os conhecedores de plantas e os registros videográficos realizadas durante o processo.

No momento da análise, as produções foram apreciadas como narrativas, visto que o diálogo esteve presente na maioria dos registros. Uma narrativa, segundo Mendes e Vaz (2009, p. 399), "é uma história bem contada", que carrega a intencionalidade do sujeito e tem seu significado negociado com o interlocutor, o qual tem a liberdade de entender a história pelo seu ponto de vista. As narrativas foram construídas pelos conhecedores de plantas dos distritos, apresentando o modo como eles compreendem o mundo e as questões relativas às plantas. Segundo Gibbs (2009, p.80), ao construir narrativas, estas dão sentido às experiências passadas e compartilham tais experiências com outras. A análise cuidadosa das narrativas conduziu à compreensão dos eventos fundamentais em suas vidas ou em suas comunidades e os contextos culturais em que vivem.

Usar as histórias construídas para constituir os dados de uma pesquisa em educação ambiental, que visou o resgate da cultura de uma determinada comunidade, foi interessante, uma vez que as narrativas personalizaram a generalização, ou seja, ao discutir as falas e as histórias, pôde-se examinar os dispositivos retóricos que as pessoas usam e a forma como elas representam e contextualizam suas expectativas e seu conhecimento pessoal. A experiência de cada sujeito da pesquisa é situada em um quadro temporal.

Uma forma de garantir a confiabilidade das discussões das falas foi compará-las com os registros de campo, também conhecidos como anotações de campo. Estes precisam ser rigorosamente desenvolvidos e ricamente detalhados. Como são essencialmente interpretativos, podem falar sobre o que é ou não dito e observado, dependendo do que o pesquisador consegue focalizar ou das opções que faz. Esses textos podem ser moldados na relação entre o pesquisador e os sujeitos da pesquisa, porque se constroem no processo de relacionamento entre eles. Durante a oficina de produção do documentário, registros em diário de campo foram realizados e utilizados para analisar o envolvimento da comunidade 7 na produção da obra.

\section{Resultados e discussão}

Acreditando na importância da mídia e na sua articulação com a educação ambiental, apresentou-se neste tópico a análise dos registros feitos durante a pesquisa, ocasião em que se procurou perceber processos de hibridação cultural aproximando mídia e cultura popular, estudantes e conhecedores de plantas. 
A produção coletiva do documentário Causos do Cerrado (2010) permitiu a aproximação do conhecimento popular com uma nova forma de transmissão de conhecimento: tradição oral e mídia em processos de hibridação cultural. Isso aconteceu de modo a acatar os diferentes posicionamentos dos envolvidos com a pesquisa que, munidos de saberes advindos de suas experiências cotidianas, mobilizam conhecimentos no seu relacionamento com as plantas. Deste modo, buscou-se em seus conhecimentos sobre as plantas o ponto de partida para integrá-lo à produção audiovisual.

A proposta da construção coletiva do documentário foi bem aceita pela comunidade. Essa aceitação de alguma maneira está relacionada à ideia de que a produção do conhecimento pode estar vinculada a outro tipo de linguagem, mais próxima não apenas dos jovens, mas especialmente dos conhecedores de plantas, que perceberam na linguagem do audiovisual uma aproximação com a oralidade. Os conhecedores de plantas e lideranças comunitárias constroem sua história a partir da oralidade, é por ela que conservam e expressam seu conhecimento do mundo. Segundo Almeida (1994), a oralidade liga-se à produção de imagens e sons por muitos fios, mas principalmente pelo realismo e pela sucessão no tempo: cadeia de imagens em movimento sucessivo/cadeia de sons sucessivos, compondo um processo de significação e sentido.

O documentário, conforme Ribeiro Júnior (2009), é compatível com o processo educativo, pois permite trabalhar não apenas com o conhecimento de plantas, mas também com a cultura, a arte como linguagem, a criatividade, a expressão e as subjetividades. Para o autor, a produção audiovisual é uma manifestação artística que desencadeia reflexões que podem ser compartilhadas em atividades coletivas, a fim de se constituir um espaço criativo, emancipador, oportunizando um ambiente em que se pode pensar juntos, e assim permite um aprofundamento das relações entre os sujeitos. Os alunos das escolas dos dois distritos trouxeram contribuições tomadas por um posicionamento crítico, amplo, estabelecendo outras formas de lidar com o conhecimento. Os mais velhos, aparentemente distantes das tecnologias do audiovisual, aproximaram-se sem receio. Segundo Souza e Gamba Júnior (2002, p. 107), “o novo deve, assim, ser incorporado como experiência simultânea de sociabilidade e transformação da subjetividade."

Estes autores alertam para possíveis zonas de conflitos entre jovens e adultos, que, inevitavelmente, ao longo do processo histórico, representam grupos que se posicionam ante as tecnologias com base em campos de visão totalmente distintos. A participação na produção coletiva parece ter minimizado a possibilidade de conflito, uma vez que todos queriam aprender sobre as técnicas do audiovisual e, de alguma maneira, se envolveram nesse processo.

A percepção de que as questões relativas aos processos de hibridação cultural estavam presentes na vivência dos moradores dos distritos acon- 
teceu a partir do momento da captação das imagens para o filme, das gravações dos depoimentos. No momento da produção do roteiro e das escolhas dos depoimentos, o que mais chamou a atenção do grupo de pesquisa foi a dedicação de todos os envolvidos no processo de produção do documentário, no registro do conhecimento popular sobre plantas.

Mas quando os conhecedores de plantas se transformam em protagonistas e contam diante das câmeras as histórias narradas trazem novos elementos que até então não se conhecia. Quando nossa experiência com o documentário avançou da produção para a captação dos depoimentos, percebeu-se como os processos de hibridação cultural estavam estabelecidos. Nossa expectativa era ouvir depoimentos muito parecidos com o registro etnobotânico: as plantas que conheciam e seus usos, os registros das festas e acontecimentos da vida nos distritos rurais. Quando os conhecedores de plantas falaram diante das câmeras, outras vozes se materializaram, mostrando que a produção coletiva de um documentário pode revelar o que está oculto, trazer para a superfície as interferências do mundo contemporâneo no cotidiano destas comunidades.

\section{As memórias narradas}

As considerações a seguir não esgotam as muitas reflexões suscitadas pela construção coletiva do documentário em causa. Apresenta-se, portanto, algumas narrativas que, isoladas de suas imagens, gestos e entonações de voz, podem perder sua vivacidade, mas que durante a discussão crítica do documentário foi possível perceber os processos de hibridação cultural das comunidades estudadas.

Neste contexto, é importante retomar alguns pesquisadores como Canclini (2008) e Wortmann (2010) ao afirmarem que hibridação não é uma fusão de culturas, como um processo fácil, ou seja, a harmonização de mundos “desengajados e beligerantes". Isso porque, "na cultura pós-moderna, a própria 'cultura' se tornou um produto, o mercado tornou-se seu próprio substituto, um produto exatamente igual a qualquer um dos itens que o constituem" (Wortmann, 2010 p. 31).

Nas narrativas dos sujeitos de pesquisa é possível identificar a preocupação deles em adquirir novos conhecimentos. De modo particular, os sujeitos aqui identificados como conhecedores de plantas estão sempre interessados em cultivar ou aprender algo novo sobre a utilização de outras espécies. Pode-se então apontar que esses indivíduos não apenas querem preservar sua cultura, mas também não se recusam a aprender o que lhes foi oferecido, tanto em termos do conhecimento popular como também dos recursos tecnológicos e científicos, como fica evidenciado na fala da 
conhecedora de planta que diz obter as folhas, frutos e sementes em uma loja em Uberlândia.

Minha vó, ela saía pra arrancar raiz, sabe? Não existiam essas raízes pra vender, aí minha vó ia porque ela fazia aqueles remédios com as raízes, então ela saía pro Cerrado pra arrancar. (...) Agora hoje em dia não tem mais aonde a gente arrancar, aqui você não encontra, você encontra comprado, lá em Uberlândia você encontra (Conhecedor de planta 02).

De acordo com Canclini (2008), em muitos países existe uma 'hierarquia dos capitais culturais', que se materializa quando "a arte vale mais que o artesanato, a medicina científica mais que a popular e a cultura escrita mais que a transmitida oralmente" (Canclini, 2008, p. 194). Na contramão dessa hierarquização criticada por esse autor, vivenciou-se no processo de produção do documentário uma superação dessa visão, percebida nas narrativas construídas pelos conhecedores de plantas no documentário. Para eles, tanto os conhecimentos adquiridos pela experiência de vida quanto os recursos científicos são importantes e podem ser conciliados.

Isso fica claro em outro trecho do documentário, quando um dos conhecedores de plantas mostra para a câmara uma cartela de comprimidos industrializados. Segundo ele, o remédio do médico nem sempre promove a cura desejada, por isso mesmo, fazendo uso do 'remédio da farmácia' (nas palavras dele), ele reconhece que também faz uso de chás. Esse senhor afirma que é necessário conciliar o uso dos recursos que hoje estão disponíveis com a preservação e a divulgação dos costumes de uma comunidade. A seguir, apresenta-se o depoimento desse conhecedor de plantas.

Eu mesmo tô tomando esse aqui [ele mostra uma cartela de comprimidos industrializados] do médico. Eu tava deitado sem poder levantar. O primeiro comprimido que eu tomei, eu levantei. É de um farmacêutico muito bom. Eu pedi pra ele [o farmacêutico] mandar pra mim. Ele mandou. Isso aqui foi muito bom pra mim (CP 06).

Corroborando com esta fala, uma das conhecedoras de plantas explica no documentário o uso que faz das plantas medicinais, buscando também o recurso médico:

Eu levei [a planta] para o médico ver. Ele falou: "Mas o que é isso?" [ênfase na entonação da voz], admirado pela cicatrização da ferida. Eu levei para o médico, porque jamais eu escondo nada de um ser humano. Eu usei isso daqui [nesse momento, ela cita o nome da espécie utilizada e abre as mãos como se estivesse 
mostrando a planta citada]; porque a pomada que o senhor me receitou não estava valendo de nada. (...) Então eu fico entre a cruz e a espada. Eu tenho fé no remédio da farmácia, mas também tenho muita fé no remédio caseiro ( $\mathrm{CP} 02$ ).

Esses trechos mostram como conhecedores de plantas não restringem seus conhecimentos ao domínio popular sobre as plantas do Cerrado ou medicinais. Há uma hibridação com o saber do mundo atual não necessariamente vinculado ao conhecimento científico. É possível perceber que, frente à câmera, outras narrativas apareceram, sugerindo uma aproximação, e até mesmo uma identificação, com a cultura midiática que está presente na vida dessas pessoas. Argumentou-se que o aparato tecnológico traz outras narrativas para as cenas, que não estavam presentes quando os conhecedores de plantas respondiam às questões abordadas no levantamento etnobotânico, cujas respostas se restringiam ao conhecimento e à valorização do conhecimento popular sobre plantas.

Momo (2010) afirma que compreender a linguagem midiática, representada por uma câmera filmadora para 'quem' irá se contar uma história, ou ainda com quem esses sujeitos irão reviver suas memórias, possibilita a intuição de verdades ou conhecimentos válidos. Para essa autora, “as novas tecnologias da comunicação afetam a forma como o conhecimento é produzido e a forma como ele circula" (Momo, 2010, p.70).

Na fala inicial do documentário, um dos conhecedores de plantas relembra como era o distrito e quais eram os costumes das pessoas da época:

O distrito há 50 anos era um lugarejo de poucas pessoas e recursos. Não tinha supermercado. Os mantimentos vinham de transporte de Uberlândia, como hoje. Comprava na venda/armazém para pagar no outro ano. [Nesse momento, ele destaca a honestidade das pessoas da época] As casas eram poucas (...) agora muitas pessoas estão construindo nos seus terrenos. (...) Mudou a plantação. Gasta-se poucas pessoas na lavoura, por conta do maquinário. As firmas necessitam de funcionários, mas em menor número. Agora as pessoas vão para Uberlândia por conta do emprego, não tem mais serviço braçal (CP 01).

Relacionando a fala desse conhecedor de plantas com seu posicionamento ao longo de toda a produção do documentário, expõe-se uma cultura em transformação, que valoriza e resgata as memórias das pessoas mais velhas, mas também considera as comodidades do mundo contemporâneo, dada pelo desenvolvimento científico e tecnológico, que tem transformado o cenário desses distritos. Diferente de outros sujeitos que aparecem no documentário, que em alguns momentos falam de suas memórias como se ainda hoje os 'costumes antigos', em sua totalidade, devessem estar presentes em nosso cotidiano. 
Outro conhecedor diz que "os mais jovens precisam aprender com os mais velhos" (CP 06). Ao expressar sua opinião, ele demonstra certo desagrado quanto à postura dos mais novos que não se interessam em conhecer as histórias do passado de sua comunidade.

Houve também a preocupação em se discutir as falas produzidas pelos estudantes envolvidos no estudo, tanto aquelas registradas no documentário quanto após as filmagens. Alguns deles afirmam que aprenderam mais sobre a natureza e sobre a utilidade das plantas, conforme se percebe nos trechos abaixo:

Eu vou poder usar mais remédio natural do que do farmacêutico. (...) A entrevista que eu mais gostei foi a da dona... [ele cita o nome de uma das conhecedoras de plantas]. Porque ela explicou bem. Falou muito sobre as plantas. Falou sobre as pessoas que usavam (Aluno 08).

Aprendi mais sobre as plantas medicinais. Eu sabia um pouco, mas passei a saber mais. Aprendi mais sobre o meio ambiente. Por exemplo, se fosse para eu tirar outras fotos sobre o meio ambiente, eu iria agora tirar foto não só da planta que estava em cima do telhado daquela casa, mas também da casa (Al 18).

Esses depoimentos referendam como foi significativo para os estudantes a participação não apenas nas gravações do documentário como também na elaboração do roteiro e demais atividades desenvolvidas nas oficinas.

O documentário produzido nesta pesquisa evidencia que a cultura popular sobre as plantas está viva, mas se encontra em processo de hibridação. Esses momentos são ricos, pois revelam que essas pessoas não estão estagnadas na sua cultura. As várias culturas coexistem, incluindo a midiática, a tecnológica, a espetacularização típica dos meios de comunicação, especialmente a televisão. Na discussão sobre o documentário, identificaram-se falas de pessoas que, mesmo reconhecidas em suas comunidades por seus conhecimentos sobre a utilização de plantas, sobretudo por suas propriedades medicinais, também fazem uso dos recursos médicos.

Nesse cenário, a discussão das narrativas do documentário Causos do Cerrado não apenas valorizou os costumes e as tradições dos moradores mais antigos, como também trouxe outras histórias mais próximas do universo dos jovens e da própria mídia. Percebeu-se que os mais jovens se interessaram pelos artefatos midiáticos, mas evidenciaram a importância, antes não percebida, do conhecimento popular sobre plantas. Já os mais velhos surpreenderam pela familiaridade com que lidaram com os artefatos tecnológicos e sua linguagem. 


\section{Algumas considerações}

O desafio assumido pela pesquisa foi articular os saberes populares com a linguagem midiática, proposto na construção coletiva do documentário. O conhecimento popular sobre plantas se estabeleceu como ponto de partida e serviu para a imersão nas comunidades estudadas, valorizando estes saberes, dotando-os de importância e possibilidades de recriação.

Buscou-se desenvolver 'um fazer' educação ambiental que valorizou o conhecimento popular sobre as plantas do Cerrado e que admite essa cultura como um campo híbrido, que integra o tempo e os saberes de gerações diferentes.

A pesquisa procurou respeitar e assim articular as muitas opiniões insurgidas ao longo do trabalho, entendendo o contexto em que os sujeitos estão inseridos. As abordagens partiram de um diálogo constante que reconheceu nas pessoas o potencial para transformar e direcionar a pesquisa, dotando-as de autonomia e liberdade para expressarem seus pontos de vista.

A educação ambiental desenvolvida na pesquisa permitiu a vivência de muitas experimentações partindo da cultura, da realidade, entendendo, assim como Larrosa (2002, p. 21), que “a experiência é o que nos passa, o que nos acontece, o que nos toca". A experiência vivida entre as pessoas que residem nos distritos com os recursos midiáticos permitiu o encontro entre os conhecedores de plantas e os alunos das escolas desses distritos.

Percebeu-se, nesta investigação, a interação entre o local e o global, representada respectivamente pela tradição do conhecimento popular sobre as plantas seguida do uso dos recursos tecnológicos empregados na produção midiática. A articulação entre esses diversos saberes nos coloca frente à necessidade do respeito à diversidade cultural que fez conviver as diferenças existentes entre essas culturas, sugerindo, nesse diálogo, a necessária superação da visão monocultural que está tão impregnada na sociedade nos dias atuais, como indica José Marín (2010).

Foi possível vivenciar uma educação ambiental pautada na vinculação de outras formas de transmitir o conhecimento popular sobre plantas, trazendo para a superfície as histórias individuais e coletiva do lugar, da origem, do modus vivendi antigo e atual, do ouvir, do falar, do respeito. Singularidades foram criadas e re-criadas na busca de viver outras possibilidades. 


\section{Colaboradores}

Todos os autores participaram em conjunto no desenvolvimento desta pesquisa e em todas as etapas de produção do manuscrito.

\section{Notas}

1 Professora do Instituto de Biologia e do Programa de Pós-Graduação em Educação da Universidade Federal de Uberlândia (UFU), Uberlândia, Minas Gerais, Brasil. Doutora em Educação pela Universidade Estadual de Campinas (Unicamp). <luciag@ umuarama.ufu.br>

Correspondência: Instituto de Biologia, Universidade Federal de Uberlândia, Campus Umuarama, Bloco 2-D, CEP 38400-902, Uberlândia, Minas Gerais, Brasil.

2 Bióloga. Mestre em Educação pela Universidade Federal de Uberlândia (UFU). <igreptton@yahoo.com.br>

3 Mestrando em Educação da Universidade Federal de Uberlândia (UFU). <gustavolofer@gmail.com>

4 Professora. Licenciada em Ciências Biológicas pela Universidade Federal de Uberlândia (UFU). <abertoldom@gmail.com>

5 Seguindo a metáfora do 'coral polifônico improvisado', de Pierre Lévy, considera-se a importância das diversas falas, do respeito às diferenças, de não sobrepor uma voz à outra, enfim, de melhorar o efeito de conjunto, mesmo que nesse momento do desenvolvimento da pesquisa ainda não se considerasse a inclusão da mídia.

6 A equipe que desenvolveu este projeto de pesquisa são os autores deste artigo. $\mathrm{O}$ envolvimento dos pesquisadores aconteceu nos seguintes níveis: um mestrado na área de Educação e dois trabalhos de iniciação científica já finalizados.

7 Os participantes do estudo foram devidamente esclarecidos sobre as atividades desenvolvidas, conforme projeto de pesquisa aprovado no Comitê de Ética em Pesquisa da Universidade Federal de Uberlândia. Na análise dos dados, os sujeitos foram identificados por códigos: CP - conhecedores de plantas; e Al - alunos das escolas participantes. O processo de construção do documentário se iniciou em fevereiro de 2010, com os primeiros contatos com as comunidades e terminou em novembro do mesmo ano. 


\section{Referências}

ALMEIDA, Milton José de. Imagens e sons: a nova cultura oral. São Paulo: Cortez, 1994.

BOSI, Ecléia. O tempo vivo da memória. 2. ed. São Paulo: Ateliê Editorial, 2003.

BURKE, Peter. Hibridismo cultural. 3. ed. São Leopoldo: Unisinos, 2010.

CANCLINI, Nestor Garcia. Culturas híbridas: estratégias para entrar e sair da modernidade. São Paulo: EDUSP, 2008.

CAUSOS DO CERRADO. Documentário. Produção coletiva. Uberlândia, Instituto de Biologia da Universidade Federal de Uberlândia, 2010. DVD, $39 \mathrm{~min}$. color. som. Disponível em: <http://www.youtube.com/ watch? $=Q$ QVk6GQFwZXg $>$. Acesso em: 2 jun. 2012.

FISCHER, Rosa Maria Bueno. Mídia, juventude e educação: modos de construir o outro na cultura. Archivos Analíticos de Politicas Educativas/ Education Policy Analysis Archives, v. 16, n. 2, jan. 2008. Disponível em: <http://epaa.asu.edu/epaa/ v16n2>. Acesso em: 10 out. 2011.

GIBBS, Graham. Análise de dados qualitativos. Tradução de Roberto Cataldo Costa. Coleção Pesquisa Qualitativa. Porto Alegre: Artmed, 2009.

GUIMARÃES, Leandro Belinaso. Fulgurações: pelos rastros da educação ambiental. In: PREVE, Ana Maria; CORRÊA, Guilherme (Orgs.). Ambientes da ecologia: perspectivas políticas e educação. 1. ed. v. 1. Santa Maria: Editora UFSM, 2007. p. 177-186.

LARROSA, Jorge. Notas sobre a experiência e o saber da experiência. Revista Brasileira de Educação, Rio de Janeiro, n. 19, p. 20-28, 2002.

LÜDKE, Menga; ANDRÉ, Marli Eliza D. A. Pesquisa em educação: abordagens qualitativas. São Paulo: EPU, 1986.
MARÍN, José. Dimensão histórica da perspectiva intercultural, educação, Estado e sociedade. In: GARCIA, R. L. (Org.). Diálogos cotidianos. Rio de Janeiro: Faperj, 2010. p. 313-330.

MARTÍN-BARBERO, Jesús. Jóvenes: comunicación e identidad. 2007. Disponível em: $<$ www.Oei.es/pensariberoamerica/ric00a03. htm>. Acesso em: 3 dez. 2008.

MENDES, Regina; VAZ, Arnaldo. Educação ambiental no ensino formal: narrativas de professores sobre suas experiências e perspectivas. Educação em Revista, Belo Horizonte, v. 25, n. 3, p. 395-411, dez. 2009.

MILANI, Juliana; GUIDO, Lucia de Fátima Estevinho; BARBOSA, Ana Angélica de Almeida. Educação ambiental a partir dos resgates dos quintais e seu valor etnobotânico no distrito de Cruzeiro dos Peixotos. Horizonte Científico, Uberlândia, v. 5, n. 1, p. 1-32, 2011.

MOMO, Mariângela. Mídia e consumo na produção da infância pós-moderna. Revista de Estudos Universitários - Pós-modernismo, Sorocaba, Uniso, v. 36, n. 1, p. 67-87, jun. 2010.

OLIVEIRA, Taíce. Educação ambiental e etnobotânica: o conhecimento dos usos de plantas do bioma Cerrado nos distritos de Tapuirama e Miraporanga, Uberlândia, MG. Monografia (Graduação em Ciências Biológicas) - Universidade Federal de Uberlândia, 2008.

ORTIZ, Renato. Cultura brasileira \& identidade nacional. 4. ed. São Paulo: Brasiliense, 2003.

RIBEIRO JÚNIOR, Djalma. Criação audiovisual na convivência dialógica em um grupo de dança de rua como processo de educação humanizadora. São Carlos. 142 p. Dissertação (Mestrado em Educação) - Centro de Educação e Ciências Humanas, Universidade Federal de São Carlos, 2009. 
SOUZA, Suzana Jobim; GAMBA JÚNIOR, Nilton. Novos suportes, antigos temores: tecnologia e confronto de gerações nas práticas de leitura e escrita. Revista Brasileira de Educação, Rio de Janeiro, set./out./nov./dez., n. 21, 2002.
WORTMANN, Maria Lúcia Castagna. Encontros interculturais, hibridações e pós-modernidade. Revista de Estudos Universitários - Pós-modernismo, Sorocaba, Uniso, v. 36, n. 1, p. 67-87, jun. 2010.

Recebido em 18/10/2011

Aprovado em 03/01/2013 